\title{
Specific interaction of pancreatic elastase and leucocytes to produce oxygen radicals and its implication in pancreatitis
}

\author{
N Tsuji, N Watanabe, T Okamoto, Y Niitsu
}

\begin{abstract}
Many previous reports using experimental animal models of pancreatitis have suggested that oxygen free radicals play an important part in initiation and development of pancreatitis. Infiltration of inflammatory cells - that is, neutrophils, lymphocytes, and monocytes - has been seen in damaged pancreatic glands of animal models and patients with pancreatitis. As neutrophils are known to be the highest producer of oxygen free radicals among these inflammatory cells, it seems plausible that oxygen free radicals produced by neutrophils have some pathoaetiological meaning in pancreatitis. This study measured the superoxide production by neutrophils obtained from patients with acute and chronic pancreatitis and then examined the effects of pancreatic enzymes on superoxide production. Patients showed significantly higher superoxide production by $4 \beta$-phorbol $12 \beta$-myristate $13 \alpha$-acetate (PMA) stimulated neutrophils than healthy controls. Among the three pancreatic enzymes, amylase, trypsin, and elastase, elastase was the only one that increased the superoxide production by PMA stimulated neutrophils, by an increment of $1 \cdot 5$-fold. It also increased the activity of nicotinamide adenine dinucleotide phosphate (NADPH) oxidase prepared from PMA stimulated neutrophils by a factor of $2 \cdot 1$. High affinity and low affinity binding sites for elastase on neutrophils were identified. These results suggest that elastase plays a part in the development of pancreatitis by enhancing superoxide production of neutrophils.
\end{abstract}

(Gut 1994; 35: 1659-1664)

Internal Medicin

(Section 4), Sapporo

Medical University

School of Medicine,

Sapporo, Japan

N Tsuji

N Watanabe

T Okamoto

Y Niitsu

Correspondence to:

Professor Y Niitsu,

Department of Internal

Medicine (Section 4),

Sapporo Medical University
School of Medicine,

South-1, West-16, Chuo-ku,

Sapporo 060, Japan.

Accepted for publication

22 March 1994 concentrations of oxygen free radical xanthine oxidase, ${ }^{5}$ and lipid peroxide ${ }^{25}$ have been noted in pancreatic tissues of these models. Pretreatment of animals with oxygen free radical scavengers; superoxide dismutase, ${ }^{124578}$ catalase, $^{12478}$ or with xanthine oxidase inhibitor, allopurinol, 679 reduced their pancreatic damage. These findings suggest that oxygen free radicals may play an important part in the initiation or development of pancreatitis.

Infiltration of inflammatory cells - that is, neutrophils, lymphocytes, and monocytes is quite common in damaged pancreatic glands of models of acute ${ }^{10}$ and chronic ${ }^{11}$ pancreatitis as well as in those of patients with acute pancreatitis ${ }^{12}$ and chronic pancreatitis at early stage. ${ }^{13}$ Neutrophils are known to be the highest producer of oxygen free radicals among these inflammatory cells, and thus it seems plausible that oxygen free radicals produced by neutrophils have some pathoaetiological meaning in pancreatitis. It has not been clear, however, whether the oxygen free radical production of neutrophils obtained from patients with pancreatitis is actually enhanced or not, and the effects of substances derived from pancreas on superoxide production by neutrophils are not known.

In this study, we, therefore, firstly measured the superoxide production by neutrophils obtained from patients with acute and chronic pancreatitis, and then examined the effects of pancreatic enzymes on superoxide production by neutrophils.

\section{Methods}

STUDY POPULATION

The control group comprised 10 healthy subjects (four men, six women) at our institution. The patient group comprised five with acute pancreatitis (four men, one women) and 12 with chronic pancreatitis (eight men, four women), diagnosed on the basis of clinical picture, laboratory tests, and on positive findings of the following: ultrasonography, computed tomography or endoscopic retrograde pancreatography. In the acute pancreatitis group, all patients showed an abnormal increase of the serum value of the pancreatic enzymes including amylase, trypsin, and elastase, and of C reactive protein. In the chronic pancreatitis group, we selected patients who showed an abnormal increase in the serum value of at least one of the three pancreatic enzymes and who had no abnormality in the serum concentrations of $\mathrm{C}$ reactive protein to eliminate the effect of systemic inflammation in other organs on neutrophil superoxide production. 
PREPARATION OF NEUTROPHILS

Neutrophils were isolated from heparinised peripheral venous blood of patients with acute and chronic pancreatitis and healthy donors by density centrifugation on Ficoll-Isopaque, followed by dextran sedimentation and hypotonic lysis of contaminating erythrocytes as reported previously. ${ }^{14}$

\section{PANCREATIC ENZYMES}

Amylase, trypsin, and elastase purified from porcine pancreas were obtained from Wako Chemical Industries, Osaka, Japan.

MEASUREMENT OF SUPEROXIDE PRODUCTION Superoxide production was measured by superoxide dismutase (Sigma Chemical, St Louis, MO) inhibitable reduction of cytochrome $c$, according to the modified method of Johnston et al. ${ }^{15}$ Briefly, neutrophils were suspended in a cuvette at a concentration of $1 \times 10^{6}$ cells $/ \mathrm{ml}$ in Hanks's balanced salt solution without phenol red, $\mathrm{pH} 7 \cdot 2$ (Gibco, Gland Island, NY), with cytochrome c acid modified from horse heart (Sigma Chemical)

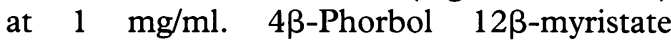
$13 \alpha$-acetate (PMA) (Sigma Chemical) was used as the stimulus at a concentration of $10 \mathrm{ng} / \mathrm{ml}$. Reactions were started by adding the PMA, cytochrome c reduction was observed for a specific time period at $550 \mathrm{~nm}$ in a dual beam recording spectrophotometer (U-3200 spectrophotometer, Hitachi, Tokyo, Japan). Superoxide production was expressed in $\mathrm{nmol} / 1 \times 10^{6}$ neutrophils, using an extinction coefficient of $21 \times 10^{3} \mathrm{M}^{-1} \mathrm{~cm}^{-1}$ corrected for the calculated length of the light path.

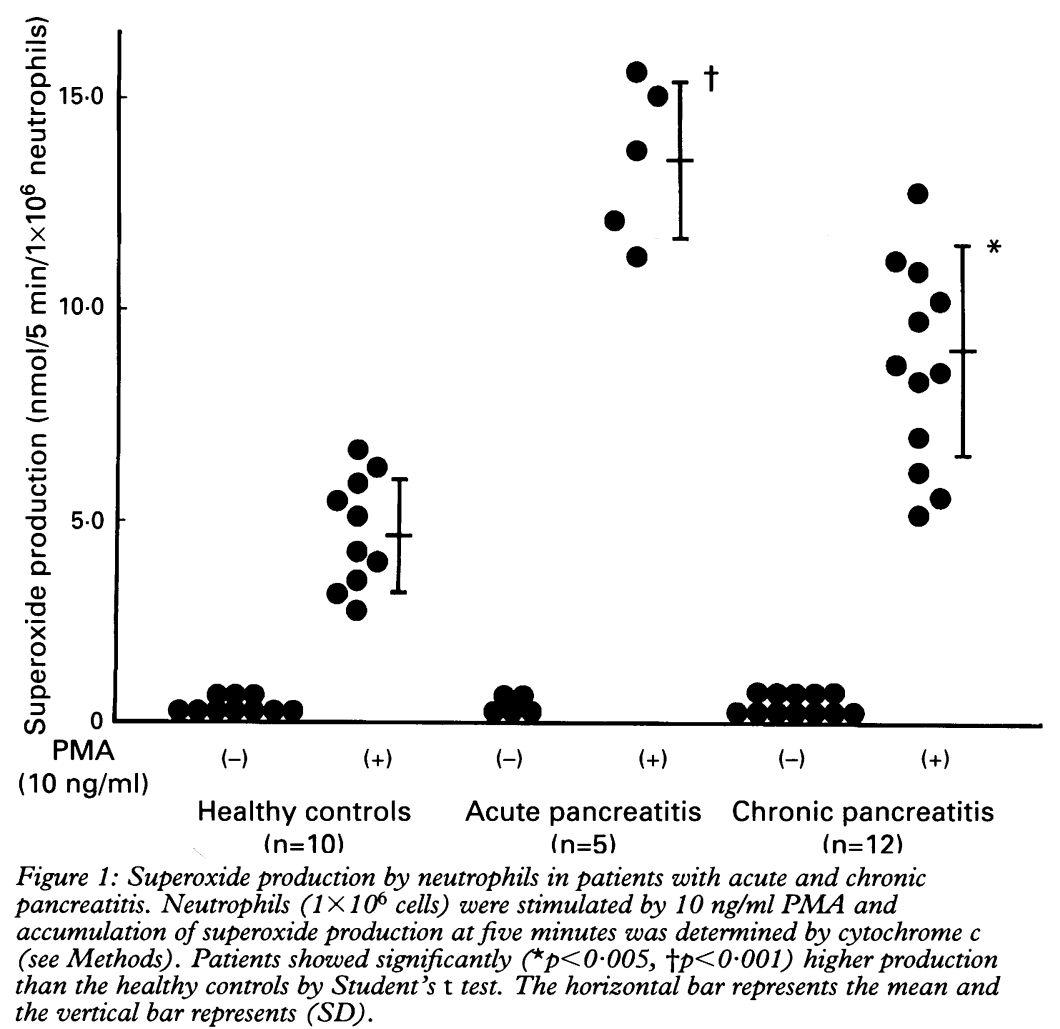

MEASUREMENT OF SPECIFIC BINDING OF ELASTASE TO NEUTROPHILS

Radioiodination of elastase was performed by the method of Bolton and Hunter ${ }^{16}$ to obtain ${ }^{125}$ I-labelled elastase with a specific activity of $7 \cdot 1 \times 10^{4} \mathrm{cpm} / \mu \mathrm{g} .2 \times 10^{6}$ neutrophils obtained from a healthy donor were incubated with various concentrations of ${ }^{125}$ I-elastase and excess amount of unlabelled elastase for one hour at $4^{\circ} \mathrm{C}$. Cells were washed three times with Hanks's balanced salt solution containing $0 \cdot 1 \%$ bovine serum albumin and were then solubilised in $1 \mathrm{M}$ $\mathrm{HCl}$, and their radioactivity was determined with a gammacounter. The number of specific binding sites of elastase per cell and the dissociation constants $(\mathrm{kd})$ were determined by Scatchard plot analysis.

PREPARATION OF PLASMA MEMBRANE FRACTION The plasma membrane fraction was prepared according to the modified method of Kakinuma et al. ${ }^{17}$ Briefly, neutrophils were suspended in $\mathrm{Ca}^{2+}$ free Krebs-Ringer/HEPES buffer $(122 \mathrm{mM} \mathrm{NaCl}, 4.9 \mathrm{mM} \mathrm{KCl}, 1.2 \mathrm{mM}$ $\mathrm{MgCl}_{2}, 17 \mathrm{mM}$ HEPES (pH 7.4)) containing $5 \mathrm{mM}$ glucose. The cell suspensions were centrifuged at $1000 \times g$ for five minutes at $4^{\circ} \mathrm{C}$. The resulting pellets were mixed with $0.5 \mathrm{ml}$ of $0.34 \mathrm{M}$ sucrose containing $10 \mathrm{mM}$ TRIS buffer ( $\mathrm{pH} \mathrm{7.4)}$ and sonicated for 15 seconds in an ice bath. The solution was then mixed with phenylmethylsulphonyl fluoride at a final concentration of $1 \mathrm{mM}$ and centrifuged at $450 \times g$ for 10 minutes to remove nuclei and unbroken cells. The supernatant was centrifuged at $100000 \times g$ for 60 minutes and the resulting pellet was suspended in a small amount of $0.34 \mathrm{M}$ sucrose. This suspension was defined as the plasma membrane fraction and stored at $-70^{\circ} \mathrm{C}$ until use.

MEASUREMENT OF NADPH OXIDASE ACTIVITY The amount of nicotinamide adenine dinucleotide phosphate (NADPH) dependent superoxide production by NADPH oxidase was taken as the superoxide dismutase inhibitable reduction of cytochrome c, according to the modified method of Park and Babior. ${ }^{18}$ Assay mixtures contained $1 \mathrm{mg} / \mathrm{ml}$ cytochrome c, 0.1 mM NADPH (Sigma Chemical), plasma membrane fraction, and 50 $\mathrm{mM}$ potasium phosphate buffer with $1.2 \mathrm{mM}$ $\mathrm{MgCl}_{2}$ to a final volume of $0.75 \mathrm{ml}$. All components except NADPH were mixed in a cuvette and equilibrated at $25^{\circ} \mathrm{C}$ for 60 seconds. Reactions were started by adding the NADPH, and cytochrome c reduction was observed at $550 \mathrm{~nm}$ for five minutes in a dual beam recording spectrophotometer (U-3200 spectrophotometer, Hitachi). Protein concentrations were determined by the Bio-Rad protein assay (Bio-Rad Laboratories, Richmond, CA). NADPH oxidase activity was expressed in $\mathrm{nmol} / \mathrm{min} / \mathrm{mg}$ protein, using an extinction coefficient of $21 \times 10^{3} \mathrm{M}^{-1} \mathrm{~cm}^{-1}$, corrected for the calculated length of the light path. 


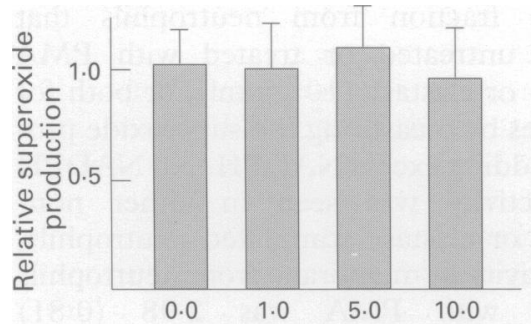

Amylase concentration (U/ml)

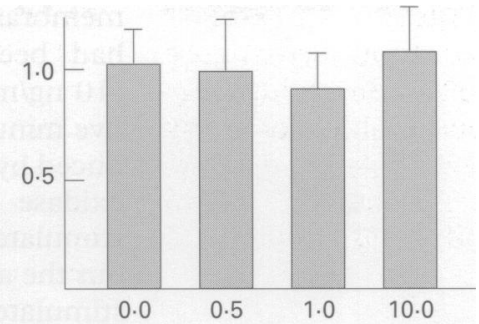

Trypsin concentration ( $\mathrm{gg} / \mathrm{ml})$

Figure 2: Effects of amylase and trypsin in combination with PMA on superoxide production by normal neutrophils. Neutrophils $\left(1 \times 10^{6}\right.$ cells) were stimulated by $10 \mathrm{ng} / \mathrm{ml}$ $P M A$ in the presence of various concentrations of amylase or trypsin and the accumulation of superoxide at five minutes was determined by cytochrome $c$. Relative superoxide production represents the ratio of superoxide production with amylase or trypsin to production in their absence. Values are mean (SD) of five separate preparations.

\section{Results}

SUPEROXIDE PRODUCTION BY PMA STIMULATED NEUTROPHILS OF PATIENTS WITH ACUTE AND CHRONIC PANCREATITIS

We investigated the superoxide production by circulating neutrophils of five patients with acute pancreatitis, 12 patients with chronic pancreatitis, and 10 controls. In the absence of stimulus, no production was seen in any of the subjects (Fig 1). Therefore, we measured the superoxide production by neutrophils treated with PMA, a well known stimulator. In healthy controls, the superoxide production mean (SD) was $4.73(1 \cdot 17)$ nmol/5 $\mathrm{min} / 1 \times 10^{6}$ neutrophils. In contrast, in the patients with acute and chronic pancreatitis, the superoxide production was significantly

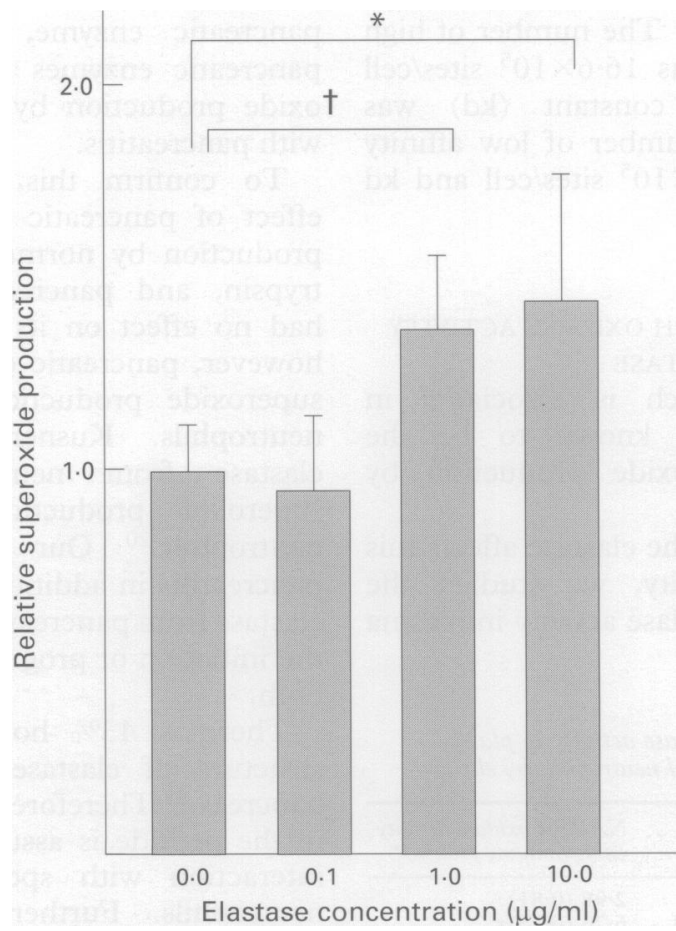

Figure 3: Effects of elastase in combination with PMA on superoxide production by normal neutrophils. Neutrophils $\left(1 \times 10^{6}\right.$ cells) were stimulated by $10 \mathrm{ng} / \mathrm{ml} \mathrm{PMA}$ in the presence of various concentrations of elastase and accumulation of superoxide at five minutes was determined by cytochrome c. Relative superoxide production represents
the ratio of production with elastase to production without elastase. Values are mean (SD) of five separate preparations. ${ }^{\star} p<0.01,+p<0.001$ by Student's t test.

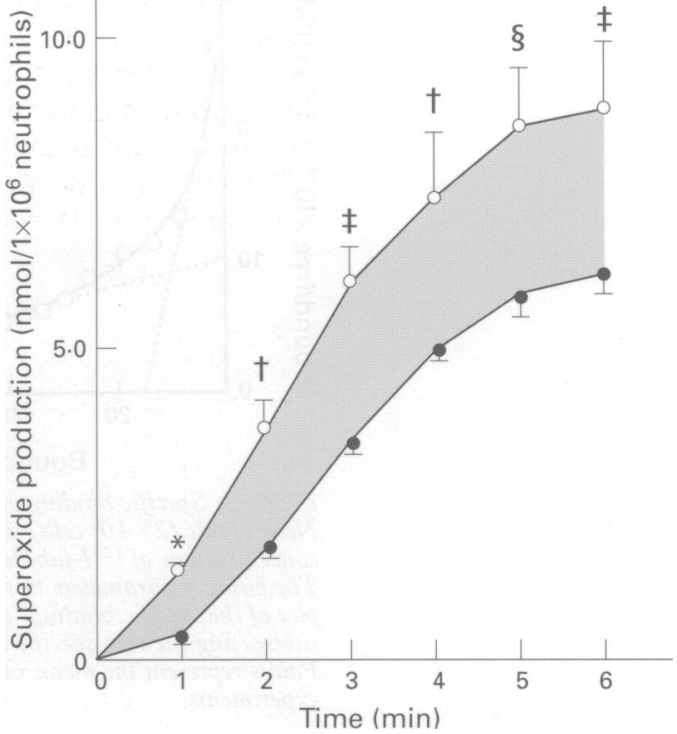

Figure 4: Effects of elastase in combination with PMA on the time course of superoxide production in normal neutrophils. Neutrophils $\left(1 \times 10^{6}\right.$ cells) were stimulated by $10 \mathrm{ng} / \mathrm{ml}$ PMA with (O-O) or without (-O) $10 \mu \mathrm{g} / \mathrm{ml}$ elastase. Accumulation of superoxide at the indicated times was determined by cytochrome $c$. The shaded area

represents superoxide production induced by the presence of elastase. Values are means (SD) of three separate preparations. ${ }^{\star} p<0.05, \dagger p<0.01, \ddagger p<0.005, \$ p<0.001$ by Student's t test.

higher at $13.50(1.83)$ and $8.57(2.41) \mathrm{nmol} / 5$ $\mathrm{min} / 1 \times 10^{6}$ neutrophils, respectively (Fig 1 ). Thus, in patients with acute and chronic pancreatitis, neutrophils are primed by some substance(s) and their responsiveness to PMA is enhanced.

EFFECTS OF PANCREATIC ENZYMES ON SUPEROXIDE PRODUCTION BY PMA STIMULATED NORMAL NEUTROPHILS

Because all patients we investigated showed an abnormal increase in serum pancreatic enzymes, we speculated that pancreatic enzymes might have primed neutrophils to undergo elicited state for production of the superoxide. To examine this possibility, we measured the superoxide production by normal neutrophils treated with various concentrations of pancreatic enzymes. Amylase, trypsin, and elastase by themselves had no effect on superoxide production (data not shown). We then measured the superoxide production by neutrophils treated with PMA $(10 \mathrm{ng} / \mathrm{ml})$ in combination with various concentrations of these three enzymes. Combined treatment with amylase and trypsin did not bring about any significant changes in superoxide production when compared with control cells - that is, neutrophils treated with PMA alone (Fig 2).

Only the combination of PMA and elastase resulted in clear increase in production of superoxide throughout the range of elastase concentrations (Fig 3). The values with elastase at 1 and $10 \mu \mathrm{g} / \mathrm{ml}$ were, respectively, 1.4 and 1.5 times that found after similar incubation with no elastase.

The shaded area in Figure 4 shows 


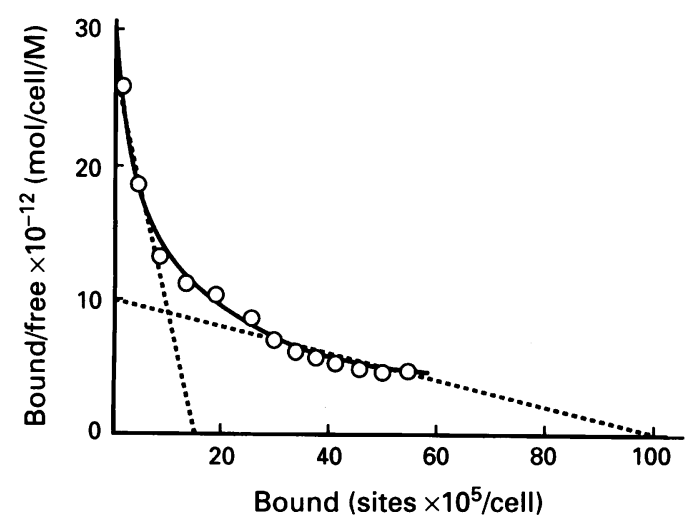

Figure 5: Specific binding of elastase to neutrophils. Neutrophils $\left(2 \times 10^{6}\right.$ cells $)$ were incubated with different concentrations of ${ }^{125} \mathrm{I}$-labelled elastase for one hour at $4^{\circ} \mathrm{C}$. The binding parameters were calculated from a Scatchard plot of the specific binding, which was obtained by subtracting the non-specific binding from the total binding. Points represent the mean values of three separate experiments.

the enhancement of superoxide production attributable to the effect of elastase. This Figure shows the time courses of the production by neutrophils incubated with and without elastase. Increment of superoxide production was seen within one minute and continued up to four minutes then reached a plateau.

\section{SPECIFIC BINDING OF ELASTASE TO} NEUTROPHILS

The number of specific binding sites for elastase on normal neutrophils was determined by Scatchard plot analysis (Fig 5). The curved line can be resolved into two components, high affinity, and low affinity. The number of high affinity binding sites was $16.6 \times 10^{5}$ sites/cell and the dissociation constant $(\mathrm{kd})$ was $101.9 \times 10^{-9} \mathrm{M}$. The number of low affinity binding sites was $99.4 \times 10^{5}$ sites/cell and $\mathrm{kd}$ was $1650 \cdot 2 \times 10^{-9} \mathrm{M}$.

AUGMENTATION OF NADPH OXIDASE ACTIVITY IN NEUTROPHILS BY ELASTASE

NADPH oxidase, which is associated in plasma membranes, is known to be the key enzyme in superoxide production by neutrophils. ${ }^{19}$

To examine whether the elastase affects this NADPH oxidase activity, we studied the changes of NADPH oxidase activity in plasma

Augmentation of NADPH oxidase activity in plasma membrane prepared from normal neutrophils by elastase

\begin{tabular}{ll}
\hline Stimulant & $\begin{array}{l}\text { NADPH oxidase activity } \\
\text { (nmol/min/mg protein) }\end{array}$ \\
\hline PMA $10 \mathrm{ng} / \mathrm{ml}$ & $2 \cdot 98(0 \cdot 81)$ \\
PMA $10 \mathrm{ng} / \mathrm{ml}+$ elastase $10 \mu \mathrm{g} / \mathrm{ml}$ & $6 \cdot 26(0 \cdot 75) \dagger$ \\
Elastase $10 \mu \mathrm{g} / \mathrm{ml}$ & Not detectable \\
No stimulant & Not detectable \\
\hline
\end{tabular}

Neutrophils $\left(1 \times 10^{7}\right.$ cells) were stimulated by $10 \mathrm{ng} / \mathrm{ml} \mathrm{PMA}$ with or without $10 \mu \mathrm{g} / \mathrm{ml}$ elastase for five minutes at $37^{\circ} \mathrm{C}$. NADPH oxidase activity in plasma membrane fraction was determined as described in Methods. *Mean (SD) in five separate experiments. +Value significantly different $(p<0.001)$ from the corresponding value for $10 \mathrm{ng} / \mathrm{ml}$ PMA by Student's $t$ test. membrane fraction from neutrophils that had been untreated or treated with PMA $(10 \mathrm{ng} / \mathrm{ml})$ or elastase $(10 \mu \mathrm{g} / \mathrm{ml})$, or both for five minutes by measuring the superoxide produced by adding excess NADPH. No NADPH oxidase activity was seen in either nonstimulated or elastase stimulated neutrophils, but the activity in membrane from neutrophils stimulated with PMA was 2.98 $(0.81)$ $\mathrm{nmol} / \mathrm{min} / \mathrm{mg}$ protein, and in that stimulated with both PMA and elastase, activity increased by a factor of $2 \cdot 1$ to $6 \cdot 26(0 \cdot 75) \mathrm{nmol} / \mathrm{min} / \mathrm{mg}$ protein (Table).

\section{Discussion}

Many previous reports have suggested that oxygen free radicals may play an important part in the initiation and development of pancreatitis, ${ }^{1-9}$ but no published studies have confirmed whether superoxide production by neutrophils is actually increased in patients with pancreatitis. Nothing is also known of the effect of substances derived from pancreas on superoxide production by neutrophils. In this study, we investigated the superoxide production by neutrophils of patients with acute and chronic pancreatitis. In the absence of stimulus, no superoxide production by neutrophils was seen in either patients or healthy controls. In these patients, however, the superoxide production by neutrophils treated with PMA was significantly higher than in healthy controls. This result suggests that patients' neutrophils had already been primed by some substance or substances. Because all patients we investigated showed an abnormal increase in the serum value of the pancreatic enzyme, we hypothesised that pancreatic enzymes might affect the superoxide production by neutrophils in patients with pancreatitis.

To confirm this, we then studied the effect of pancreatic enzymes on superoxide production by normal neutrophils. Amylase, trypsin, and pancreatic elastase themselves had no effect on its superoxide production, however, pancreatic elastase did enhance the superoxide production of PMA stimulated neutrophils. Kusner and King reported elastase from neutrophil increased the superoxide production by PMA stimulated neutrophils. ${ }^{20}$ Our results show that in pancreatitis in addition to neutrophil elastase, elastase from pancreas itself also participates in the initiation or progression of pancreatitis, or both.

There is $43 \%$ homology in the primary structure of elastases from neutrophil and pancreas. ${ }^{21}$ Therefore the homologous portion of the peptide is assumed to be essential for interaction with specific binding sites on neutrophils. Further study is needed to elucidate this assumption.

We measured the superoxide production by neutrophils obtained from a patient with chronic pancreatitis who showed an abnormal increase in the serum value of elastase. Although the production by neutrophils stimulated with PMA alone was higher than 
that of neutrophils from healthy controls, the enhancing effect of elastase on superoxide production that had been shown in healthy controls was not seen (data not shown). It seems plausible that the neutrophils in patients with pancreatitis had already been primed by elastase and had reached the maximum primed state.

In this study, we used PMA as a stimulator for superoxide production by neutrophils. Pancreatitis patients do not produce PMA. It is known, however, that endotoxin, ${ }^{22}$ immune complex, ${ }^{23}$ anaphylatoxins, ${ }^{24} 25$ terminal complement complex, ${ }^{25}$ tumour necrosis factor, ${ }^{22}$ and platelet activating factor, ${ }^{26}$ which have the ability to induce superoxide production by neutrophils, are increased in serum or pancreatic tissue of patients or animal models of pancreatitis. An experiment using tumour necrosis factor as a stimulator in place of PMA also showed significant production of superoxide (data not shown). It seems plausible that this and others of the above substances have this effect in patients with pancreatitis.

To exhibit its enhancing effect on neutrophil superoxide production, elastase has to bind specifically to neutrophils and induce the signal transduction through specific binding sites. Recently, specific binding sites of pancreatic phospholipase $A_{2}$ were found on several rat and human cells, ${ }^{27-29}$ and it was confirmed that pancreatic phospholipase $A_{2}$ induced contraction of guinea pig lung parenchyma through its specific binding site. ${ }^{29}$ There are no reports, however, concerning the specific binding sites of other pancreatic enzymes or the elastase family. This study provided the first evidence for the presence of high affinity and low affinity specific binding sites for elastase on neutrophils. We are now conducting further studies on the action by elastase on the binding sites on neutrophils.

NADPH oxidase is known to be the key enzyme in superoxide production by neutrophils. We examined whether its activity is affected by signal transduction through neutrophil binding elastase. The activity of NADPH oxidase in plasma membrane fraction from neutrophils simultaneously stimulated with PMA and elastase increased significantly compared with that in neutrophils stimulated with PMA alone. These results show that enhancement of NADPH oxidase activity is one of the mechanisms by which elastase increases the superoxide production by neutrophils.

With regard to the role of elastase in initiation and development of pancreatitis, the necropsy findings of pancreas tissues in experimental pancreatitis model using $\operatorname{dogs}^{30-32}$ and in patients with haemorrhagic pancreatitis $^{33}$ have suggested only a role for elastase in vascular injury by dissolving the elastic fibres in vessel walls. Our findings point to a new possibility that elastase affects development of pancreatitis by directly increasing the production of the destructive superoxide molecule.
1 Schoenberg MH, Buchler M, Gaspar M, Stinner A, Younes $M$, Melzner I, et al. Oxygen free radicals in acute M, Melzner I, et al. Oxygen free radicals
pancreatitis of the rat. Gut 1990; 31: 1138-43.

2 Nonaka A, Manabe T, Kyogoku T, Tamura K, Tobe T. Changes in lipid peroxide and oxygen radical scavengers in cerulein-induced acute pancreatitis. Imbalance between the offense and defense systems. Digestion 1990; 47: $130-7$.

3 Gough DB, Bolye B, Joyce WP, Delaney CP, McGeeney $\mathrm{KF}$, Gorey TF, et al. Free radical inhibition and serial chemiluminescence in evolving experimental pancreatitis. Brf Surg 1990; 77: 1256-9.

4 Schoenberg $M H$, Buchler $M$, Baczako K, Bultmann B, Younes M, Gasper M, et al. The involvement of oxygen radicals in acute pancreatitis. Klin Wochenschr 1991; 69: radicals $1025-31$.

5 Nonaka A, Manabe T, Tamura $\mathrm{K}$, Asano N, Imanishi $\mathrm{K}$, Tobe T. Changes of xanthine oxidase, lipid peroxide and superoxide dismutase in mouse acute pancreatitis. Digestion 1989; 43: 41-6.

6 Rutledge PL, Saluja AK, Powers RE, Steer ML. Role of oxygen-derived free radicals in diet-induced hemorrhagic pancreatitis in mice. Gastroenterology 1987; 93: 41-7.

7 Steer ML, Rutledge PL, Powers RE, Saluja M, Saluja AK. The role of oxygen-derived free radicals in two models of experimental acute pancreatitis: effects of catalase, superoxide dismutase dimethylsulfoxide, and allopurinol. Klin Wochenschr 1991; 69: 1012-7.

8 Sanfey H, Bulkley GB, Cameron JL. The role of oxygenderived free radicals in the pathogenesis of acute pancrederived free radicals in the pathogen

9 Sanfey H, Bulkley GB, Cameron JL. The pathogenesis of acute pancreatitis. The source and role of oxygen-derived acute pancreatitis. The source and role of oxygen-derived free radicals in three differ

10 Adler G, Hupp T, Kern HF. Course and spontaneous regression of acute pancreatitis in the rat. Virchows Arch $A$ Pathol Anat Histopathol 1979; 382: 31-47.

11 Okumura N, Sakakibara A, Hayakawa T, Noda A. Pancreatic endocrine function in experimental pancreatolithiasis in dogs. Am $\mathcal{F}$ Gastroenterol 1982; 77: 392-6.

12 Aho HJ, Nevalainen TJ, Havia VT, Heinonen RJ, Aho AJ. Human acute pancreatitis. A light and electron microscopic study. Acta Path Microbiol Immunol Scand Sect A 1982; 90: 367-73.

13 Uys CJ, Bank S, Marks IN. The pathology of chronic pancreatitis in Cape Town. Digestion 1973; 9: 454-68.

14 Kitagawa S, Takaku F, Sakamoto S. A comparison of the superoxide-releasing response in human polymorphonuclear leukocytes and monocytes. F Immunol 1980; 125: 359-64.

15 Johnston RB Jr, Godzik CA, Cohn ZA. Increased superoxide anion production by immunologically activated and chemically elicited macrophages. $\mathcal{f}$ Exp Med 1978; 148: 115-27.

16 Bolton AE, Hunter WM. The labelling of proteins to high specific radioactivities by conjugation to a ${ }^{125} \mathrm{I}$-containing acylating agent. Application to the radioimmunoassay. Biochem $\mathcal{F}$ 1973; 133: 529-39.

17 Kakinuma K, Kaneda M, Chiba T, Ohnishi T. Electron spin resonance studies on a flavoprotein neutrophil spin resonance studies on a flavoprotein neutrophil participation in NADPH oxidase. 7 Biol Chem 1986; 261: participation

18 Park JW, Babior BM. The translocation of respiratory burst oxidase components from cytosol to plasma membrane is regulated by guanine nucleotides and diacylglycerol. $\mathfrak{f} \mathrm{Bio}$ Chem 1992; 267: 19901-6.

19 Dewald B, Baggiolini M, Curnutte JT, Babior BM. Subcellular localization of the superoxide-forming enzyme in human neutrophils. f Clin Invest 1979; 63: 21-9.

20 Kusner DJ, King CH. Protease-modulation of neutrophil superoxide response f Immunol 1989; 143: 1696-702.

21 Sihha S, Watorek W, Karr S, Giles J, Bode W, Travis J. Primary structure of human neutrophil elastase. Proc Natl Acad Sci USA 1978; 84: 2228-32.

22 Exley AR, Leese T, Swann RA, Cohen J. Endotoxaemia and serum tumour necrosis factor as prognostic markers in severe acute pancreatitis. Gut 1992; 33: 1126-8.

23 Sonia J, Grazia DG, Mariano M, Huerta JMM, Sirois P, Braquet P. Immune complex induced pancreatitis: effect of BN52021, a selective antagonist of platelet-activating factor. Prostaglandins 1988; 35: 757-70.

24 Roxvall L, Bengtson A, Heideman M. Anaphylatoxin generation in acute pancreatitis. F Surg Res 1989; 47: 138-43.

25 Roxvall LI, Bengston LA, Heideman M. Anaphylatoxins and terminal complement complexes in pancreatitis. Evidence of complement activation in plasma and ascites fluid of patient with acute pancreatitis. Arch Surg 1990; 125: $918-21$.

26 Zhou W, Chao W, Levine BA, Olson MS. Evidence for platelet-activating factor as a late-phase mediator of chronic pancreatitis in the rat. Am $f$ Pathol 1990; 137: chronic pa $1501-8$.

27 Hanasaki $\mathrm{K}$, Arita $\mathrm{H}$. Purification and characterization of a high-affinity binding protein for pancreatic-type of a high-affinity binding protein for pancreatic-type phospholipa

28 Hanasaki K, Arita H. Characterization of a high affinity binding site for pancreatic-type phospholipase $\mathrm{A}_{2}$ in the rat. Its cellular and tissue distribution. F Biol Chem 1992; 267: 6414-20. 
29 Kanemasa T, Arimura A, Kishino J, Ohtani M, Arita H. Contraction of guinea pig lung parenchyma by a pancreatic type phospholipase $A_{2}$ via its specific binding site. FEBS Lett 1992; 303: 217-20.

30 Geokas MC, Murphy DR, Mckenna RD. The role of elastase in acute pancreatitis. I. Intrapancreatic elastolytic activity in bile-induced acute pancreatitis in dogs. Arch Pathol 1968; 86: 117-26.

31 Geokas MC. The role of elastase in acute pancreatitis.
II. Intrapancreatic elastolytic activity in trypsininduced acute pancreatitis in dogs. Arch Pathol 1968; 86: $127-34$.

32 Geokas MC. The role of elastase in acute pancreatitis. III.

The destructive capacity of elastase on pancreatic tissue in vivo and in vitro. Arch Pathol 1968; 86: 135-41.

33 Geokas MC, Rinderknecht H, Swanson V, Haverback BJ. The role of elastase in acute hemorrhagic pancreatitis in man. Lab Invest 1968; 19: 235-9. 